\title{
Longitudinal change in c-terminal fibroblast growth factor 23 and outcomes in patients with advanced chronic kidney disease
}

\author{
Helen V. Alderson ${ }^{1,2^{*}}$, Rajkumar Chinnadurai' , Sara T. Ibrahim ${ }^{1,3}$, Ozgur Asar ${ }^{4}$, James P. Ritchie', \\ Rachel Middleton ${ }^{1}$, Anders Larsson ${ }^{5}$, Peter J. Diggle ${ }^{6}$, Tobias E. Larsson ${ }^{7}$ and Philip A. Kalra ${ }^{1}$
}

\begin{abstract}
Background: Fibroblast growth factor23 (FGF23) is elevated in CKD and has been associated with outcomes such as death, cardiovascular (CV) events and progression to Renal Replacement therapy (RRT). The majority of studies have been unable to account for change in FGF23 over time and those which have demonstrate conflicting results. We performed a survival analysis looking at change in c-terminal FGF23 (cFGF23) over time to assess the relative contribution of CFGF23 to these outcomes.

Methods: We measured cFGF23 on plasma samples from 388 patients with CKD 3-5 who had serial measurements of CFGF23, with a mean of 4.2 samples per individual. We used linear regression analysis to assess the annual rate of change in CFGF23 and assessed the relationship between time-varying CFGF23 and the outcomes in a cox-regression analysis.

Results: Across our population, median baseline eGFR was $32.3 \mathrm{mls} / \mathrm{min} / 1.73 \mathrm{~m}^{2}$, median baseline cFGF23 was 162 relative units/ml (RU/ml) (IQR 101-244 RU/mL). Over 70 months (IQR 53-97) median follow-up, 76 (19.6\%) patients progressed to RRT, 86 (22.2\%) died, and 52 (13.4\%) suffered a major non-fatal CV event. On multivariate analysis, longitudinal change in CFGF23 was significantly associated with risk for death and progression to RRT but not non-fatal cardiovascular events.
\end{abstract}

Conclusion: In our study, increasing CFGF23 was significantly associated with risk for death and RRT.

Keywords: cFGF23, CKD, Survival outcomes

\section{Background}

Fibroblast growth factor-23 (FGF23) is a regulatory hormone produced by osteocytes and osteoblasts; it plays a significant role in phosphate homeostasis [1]. FGF23 is up regulated early in CKD and functions as an important regulator of phosphate, promoting phosphaturia and reducing the production of 1,25-dihydroxyvitamin D [2].

*Correspondence: Helen.alderson@srft.nhs.uk

${ }^{2}$ Department of Renal Medicine, Salford Royal Hospital, Level 2, Hope

Building, Stott Lane, Salford M6 8HD, UK

Full list of author information is available at the end of the article
Recognition of FGF23 as an important pathological factor in CKD has made it a prime biomarker to investigate in clinical studies and a potential target for future therapeutic intervention $[3,4]$.

Numerous studies have investigated the relationship between baseline FGF23 and clinical outcomes in CKD. FGF23 has been shown to associate with risk for death [5-10] and cardiovascular events [7, 9, 11-13] in both dialysis and non-dialysis populations.

There is growing understanding of the underlying pathophysiological mechanisms. FGF23 causes reversible hypertrophy of cardiac myocytes in mice [14] and 
in myocardial autopsy samples from dialysis patients [15]. High levels of FGF23 are positively correlated with increasing blood pressure [16] and pulse pressure [17] in CKD, this may be due to impairment of endothelial dependent vasorelaxation [18], High levels of FGF23 are associated with arterial stiffness [19], atherosclerosis [19, 20] and aortic valve calcifications [21] in CKD. FGF23 can directly stimulate the hepatic production of inflammatory cytokines such as $\mathrm{C}$ reactive protein [22]. High FGF23 impairs host defense in mice and CKD patients [23], increasing risk of infection related hospitalizations in older adults [24].

Elevated levels of FGF23 have been associated with risk for progression of kidney disease and renal replacement therapy $[7-10,25,26]$ and in non-CKD populations they have been shown to predict incident CKD $[27,28]$. More recent studies have investigated whether FGF23 can improve reclassification of risk [29].

Although these clinical studies have identified that FGF23 is an important risk factor in CKD, the majority do not account for change in FGF23 over time. There is individual variability in FGF23 levels but studies in both healthy participants [30] and CKD patients have shown that high levels confer increased risk [31].

Three studies have sought to investigate change in FGF23 over time and the effect on risk for death in CKD patients $[5,7,8]$. The study by de Bouma et al. showed that the rate of change in FGF23 was not predictive of mortality, whereas the study by Isakova et al. demonstrated that rapidly rising FGF23 levels conferred an increased risk for death in comparison to stable levels.

Our study examined cFGF23 levels over time in a cohort of 388 patients selected from the Salford Kidney Study (SKS) to analyse the relationship between change in cFGF23 and the clinical outcomes of death, renal progression and cardiovascular events.

\section{Methods}

\section{Patient population}

The Salford kidney study (SKS), Salford, UK is a prospective observational study to investigate outcomes in kidney disease. Three hundred eighty-eight subjects recruited between 2004 and 2013 who had sufficient stored baseline and serial plasma samples were selected for this analysis. Details of the SKS cohort (previously known as the chronic renal insufficiency standards implementation study, CRISIS) have been published previously [32-35]. In brief, patients aged 18 years or older who are referred to our renal center for management of CKD and have an eGFR $\leq 60 \mathrm{mls} / \mathrm{min} / 1.73 \mathrm{~m}^{2}$ are eligible for recruitment. Patients are managed in accordance with standard clinical practice guidelines and are followed up until death or initiation of renal replacement therapy (dialysis or transplantation). Demographic data are recorded at baseline and annually during study follow up. Blood samples are drawn for standard clinical tests and additional samples stored for subsequent biomarker analyses. Three hundred eighty-eight patients had repeated measurements of cFGF23, with a mean of 4.2 measurements per individual. Time zero was defined as the baseline sample date and follow-up was until death, initiation of renal replacement therapy, or April 2014. Date and cause of death was obtained from the Office of National Statistics (ONS), date of initiation of renal replacement therapy (RRT) was obtained from the electronic patient records. Major adverse cardiovascular events were recorded during study follow-up and defined as myocardial infarction, coronary angiogram plus angioplasty or stenting, coronary artery bypass graft surgery or stroke. Any patient reported events were verified against primary care and hospital records to ensure accuracy of reporting.

\section{Biomarker analysis}

All biomarker analyses were performed on lithiumheparin plasma samples that had been stored at $-80^{\circ} \mathrm{C}$. cFGF23 was measured in 2014 using a 2nd generation two-site enzyme linked immunosorbent assay (ELISA) supplied by Immutopics (San Clemente, CA, USA) detecting intact FGF23 and its c-terminal fragments. eGFR was calculated from IDMS calibrated creatinine measurements using the 4-variable Modified Diet in Renal Disease (MDRD) study equation [36].

\section{Statistical analysis}

The annual rate of change of cFGF23 (delta cFGF23) and the annual rate of change in estimated glomerular filtration rate (delta eGFR) were calculated by linear regression analysis using all available values between study baseline and endpoint. The cohort was split into four quartiles based on delta cFGF23 values The baseline characteristics and outcomes were compared across these cFGF23 quartiles. Continuous variables were expressed as median (IQR), and $p$-value of the difference between the groups was estimated by Kruskal Wallis $\mathrm{H}$ test. Categorical variables were expressed as numbers (\%) and p-value of the difference between the groups being calculated by the Chi-square test.

Univariate and multivariate Cox-regression analysis was used to evaluate the strength of association between the cFGF23 quartiles and the outcomes RRT, all-cause mortality prior RRT, and non-fatal cardiovascular events. The univariate analysis included all baseline characteristics, while multivariate models incorporated factors that were significant in the univariate models in a stepwise approach.. Kaplan Meier curves were used to demonstrate the difference in survival patterns between the 
Table 1 Baseline demographic data and outcomes stratified by quartiles of delta FGF23 value

\begin{tabular}{|c|c|c|c|c|c|c|}
\hline \multirow[t]{2}{*}{ Variables } & \multirow[b]{2}{*}{ Total 388} & \multirow[b]{2}{*}{$\begin{array}{l}\text { Lower quartile (Q1) } \\
\text { (97) }\end{array}$} & \multicolumn{3}{|c|}{ Delta cFGF23 (RU/mL/year) } & \multirow[b]{2}{*}{$p$-Value } \\
\hline & & & $\begin{array}{l}\text { Lower middle quartile } \\
\text { (Q2) (97) }\end{array}$ & $\begin{array}{l}\text { Upper middle quartile } \\
\text { (Q3) (97) }\end{array}$ & $\begin{array}{l}\text { Upper quartile (Q4) } \\
\text { (97) }\end{array}$ & \\
\hline $\begin{array}{l}\text { Delta cFGF23 RU/mL/ } \\
\text { year }\end{array}$ & $11.9(-3$ to 57.6$)$ & $-13.9(-32.3$ to -6.7$)$ & 3.3 (0.75 to 6.7) & 26.4 (17.5 to 37.1$)$ & 168.5 (85.4 to 407.2 ) & $<0.001$ \\
\hline Age, years & $62(52-71)$ & $62(50-71)$ & $62(52-71)$ & $64(55-70)$ & $61(52-71)$ & 0.968 \\
\hline Sex, (Male) & $245(63.1 \%)$ & $56(57.7 \%)$ & 70 (72.2\%) & $58(59.8 \%)$ & $61(63 \%)$ & 0.166 \\
\hline Ethnicity, (Caucasian) & 370 (95.4\%) & $93(95.9 \%)$ & 91 (93.8\%) & 94 (96.9\%) & $92(94.8 \%)$ & 0.623 \\
\hline $\begin{array}{l}\text { Current or former } \\
\text { smoker }\end{array}$ & $226(58.2 \%)$ & $52(53.6 \%)$ & $51(52.6 \%)$ & $58(59.8 \%)$ & 65 (67\%) & 0.151 \\
\hline Diabetes & 97 (25\%) & $21(21.6 \%)$ & $22(22.7 \%)$ & $27(27.8 \%)$ & $27(27.8 \%)$ & 0.639 \\
\hline $\begin{array}{l}\text { Prior cardiovascular } \\
\text { event }\end{array}$ & $84(21.6 \%)$ & $21(21.6 \%)$ & $22(23.7 \%)$ & $20(20.6 \%)$ & $21(21.6 \%)$ & 0.963 \\
\hline Heart failure at baseline & $36(9.3 \%)$ & $11(11.3 \%)$ & $9(9.3 \%)$ & $9(9.3 \%)$ & $7(7.2 \%)$ & 0.806 \\
\hline $\begin{array}{l}\text { Mean baseline systolic } \\
\text { blood pressure (mmHg) }\end{array}$ & 135 (123-150) & $133(117-150)$ & $135(123-150)$ & $139(129-152)$ & $133(123-150)$ & 0.183 \\
\hline \multicolumn{7}{|l|}{ Primary renal disease } \\
\hline $\begin{array}{l}\text { Diabetic nephropa- } \\
\text { thy }\end{array}$ & $52(13.4 \%)$ & $12(12.4 \%)$ & $5(5.2 \%)$ & $16(16.5 \%)$ & 19 (19.6\%) & \\
\hline Hypertension & $48(12.4 \%)$ & $11(11.3 \%)$ & $12(12.4 \%)$ & $15(15.5 \%)$ & $10(10.3 \%)$ & \\
\hline Renovascular disease & $49(12.6 \%)$ & $16(16.5 \%)$ & $15(15.5 \%)$ & $7(7.2 \%)$ & $11(11.3 \%)$ & \\
\hline Glomerulonephritis & $87(22.4 \%)$ & 29 (29.9\%) & $23(23.7 \%)$ & $16(16.5 \%)$ & $19(19.6 \%)$ & 0.004 \\
\hline ADPKD & $32(8.2 \%)$ & $5(5.2 \%)$ & $4(4.1 \%)$ & $11(11.3 \%)$ & $12(12.4 \%)$ & \\
\hline Other & $59(15.2 \%)$ & $10(10.3 \%)$ & $24(24.7 \%)$ & $14(14.4 \%)$ & $11(11.3 \%)$ & \\
\hline Unknown & $28(7.21 \%)$ & $6(6.2 \%)$ & $9(9.3 \%)$ & $7(7.2 \%)$ & $6(6.2 \%)$ & \\
\hline \multicolumn{7}{|c|}{ Baseline laboratory results } \\
\hline cFGF23 (RU/mL) & $162(101-244)$ & $218(129-332)$ & $103(78-160)$ & $141(100-182)$ & $211(157-321)$ & $<0.001$ \\
\hline Creatinine (mmol/L) & $180(140-241)$ & $189(140-252)$ & $157(126-188)$ & $169(133-213)$ & $227(181-290)$ & $<0.001$ \\
\hline $\begin{array}{l}\text { MDRD eGFR (mL/ } \\
\left.\mathrm{min} / 1.73 \mathrm{~m}^{2}\right)\end{array}$ & $32.3(22.9-43.3)$ & $30(21-45)$ & $41.2(30.8-51.7)$ & $33.4(26.1-41.8)$ & $24.5(18.8-33.7)$ & $<0.001$ \\
\hline Phosphate (mmol/L) & $1.09(0.95-1.25)$ & $1.07(.094-1.27)$ & $1.02(0.88-1.16)$ & $1.09(0.93-1.24)$ & $1.16(1.01-1.31)$ & 0.001 \\
\hline Calcium (mmol/L) & $2.25(2.17-2.32)$ & $2.27(2.18-2.34)$ & $2.25(2.18-2.31)$ & $2.25(2.16-2.32)$ & $2.23(2.14-2.31)$ & 0.198 \\
\hline Albumin $(g / L)$ & $44(42-46)$ & $45(42-46)$ & $44(42-46)$ & $44(41-46)$ & $43(41-44)$ & $<0.001$ \\
\hline Haemoglobin (g/L) & $128(117-140)$ & $126(116-137)$ & $134(124-143)$ & $130(120-141)$ & $122(111-132)$ & $<0.001$ \\
\hline PTH (pg/mL) & $54(31-101)$ & $54(30-94)$ & $35.5(25-59.5)$ & $50(33-101)$ & $90(52-178)$ & $<0.001$ \\
\hline CRP (mg/L) & $3.35(1.4-6.87)$ & $2.8(1.4-5.95)$ & $2.9(1.5-5.5)$ & $3.9(1.4-8.7)$ & $3.6(1.4-8.8)$ & 0.333 \\
\hline $\begin{array}{l}\text { Urinary protein } \\
(\mathrm{g} / 24 \mathrm{~h})\end{array}$ & $0.15(0.06-0.43)$ & $0.11(0.06-0.33)$ & $0.12(0.06-0.30)$ & $0.12(0.05-0.44)$ & $0.31(0.16-0.57)$ & $<0.001$ \\
\hline \multicolumn{7}{|l|}{ Outcomes } \\
\hline $\begin{array}{l}\text { Delta eGFR mL/ } \\
\mathrm{min} / 1.73 \mathrm{~m}^{2} / \text { year }\end{array}$ & $-1.2(-2.76$ to 0.02$)$ & $-0.08(-0.09$ to 0.97$)$ & -0.62 ( -1.87 to 0.27$)$ & $-1.6(-3.1$ to -0.54$)$ & $-2.68(-4.6$ to -1.5$)$ & $<0.001$ \\
\hline $\begin{array}{l}\text { Death prior to RRT } \\
\text { (\%) }\end{array}$ & $86(22.2 \%)$ & $15(15.5 \%)$ & $13(13.4 \%)$ & $26(26.8 \%)$ & $32(33 \%)$ & 0.002 \\
\hline RRT (\%) & $76(19.6 \%)$ & $8(8.2 \%)$ & $6(6.2 \%)$ & $13(13.4 \%)$ & $49(50.5 \%)$ & $<0.001$ \\
\hline $\begin{array}{l}\text { Total CV events dur- } \\
\text { ing Follow-up (\%) }\end{array}$ & $52(13.4 \%)$ & $10(10.3 \%)$ & $9(9.3 \%)$ & 19 (19.6\%) & $14(14.4 \%)$ & 0.138 \\
\hline $\begin{array}{l}\text { Follow up time } \\
\text { (months) }\end{array}$ & $70(52.6-96.8)$ & $69(53-97)$ & $89(59-101)$ & $83(55-101)$ & $57(43-75)$ & $<0.001$ \\
\hline
\end{tabular}

Continuous variables are expressed as median (IQR) and $p$ value of the difference between the groups by Kruskal Wallis $\mathrm{H}$ test. Categorical variables are expressed as numbers (\%) and $p$ value of the difference between the groups by Chi- square test

ADPKD autosomal dominant polycystic kidney disease, PTH parathormone, CRP-c-reactive protein, CFGF23 Fibroblast growth factor23, Cardiovascular (CV) eventdefined as non-fatal stroke or myocardial infarction, coronary angiogram plus angioplasty or stenting, coronary artery bypass graft surgery. Heart failure defined as left ventricular ejection fraction $\leq 50 \%$ or diastolic dysfunction on echocardiogram or a clinical diagnosis of heart failure with no other alternative cause for symptoms. RRT- renal replacement therapy, eGFR-estimated glomerular filtration rate by Modification of Diet in Renal Disease (MDRD) equation 
quartiles with the log-rank test used to test the statistical significance. Throughout the analysis, a $p$-value $<0.05$ was taken to be statistically significant. All analysis was performed using SPSS- Version 24 registered to the University of Manchester.

\section{Results}

\section{Summary data}

Baseline demographics for the cohort stratified according to quartiles of delta cFGF23 are presented in Table 1. The median age was 62 years (IQR $52-71$ ), $63.8 \%$ of the patients were male, $96 \%$ were Caucasian and $25 \%$ were diabetic, $52(13.4 \%)$ patients had suffered a prior major cardiovascular event. The median baseline MDRD eGFR was $32.3 \mathrm{ml} / \mathrm{min} / 1.73 \mathrm{~m}^{2}$. The median study follow up was 70 months (IQR 53 to 97 months).

\section{cFGF23 measurement}

Three hundred eighty-eight patients had 3 or more serial measurements of cFGF23. The mean number of measurements per individual was 4.2 (SD 1.5, range 3-9) with a median time of 1.1 years between successive measurements. Across the whole cohort the median baseline level of cFGF23 was $162 \mathrm{RU} / \mathrm{ml}$ (IQR 101-244 RU/mL).

\section{Survival analysis}

There was a high rate of progression to RRT in our study, with $76(19.6 \%)$ of patients reaching this endpoint. There were 86 (22.2\%) deaths prior to initiation of RRT. During follow-up, $13.4 \%$ of the cohort suffered at least one nonfatal major cardiovascular event.

\section{Rate of change in FGF23 and outcomes}

When quartiles of delta cFGF23 were compared to clinical outcomes, there was a significant difference in risk for death, RRT and delta eGFR between those in the highest and lowest quartiles $(p=0.002, p<0.001$ and $p<0.001$ respectively) (Table 1 ). There was no significant difference in non-fatal major cardiovascular events between quartiles of delta cFGF23. There were insufficient data available on cause of death to look at associations with fatal cardiovascular events. In fully adjusted multivariate Cox-regression analysis there was a significant association between higher delta cFGF23 and risk for death (HR 1.46, 95\% CI 1.16-1.83, $p=0.001$ ) and renal replacement therapy (HR 2.06, 95\% CI 1.60-2.67, $p<0.001$ ), although there remained a strong inverse correlation between change in eGFR and cFGF23. There was no significant association between delta cFGF23 and non-fatal cardiovascular events in our analysis (HR 1.31, 95\% CI 0.99-1.74, $p=0.053$ ). Results of the Cox regression analyses in respect to these outcomes are shown in Table 2 and Supplementary Tables 1, 2 and 3. Kaplan-Meier curves in respect to each outcome are shown in Fig. 1.

\section{Discussion}

We investigated the relationship between change in cFGF23 over time and risk for death, progression to RRT and cardiovascular events. In our study cFGF23 was associated with risk for death, declining eGFR and RRT, but not with non-fatal cardiovascular events.

Numerous studies have shown baseline cFGF23 to associate with risk for RRT $[9,10]$. We have previously

Table 2 Cox-regression models for outcomes

\begin{tabular}{|c|c|c|c|c|c|c|}
\hline & \multicolumn{2}{|c|}{ All-cause mortality prior RRT } & \multicolumn{2}{|c|}{ Renal Replacement Therapy (RRT) } & \multicolumn{2}{|c|}{ Cardiovascular event } \\
\hline & HR $(95 \% \mathrm{Cl})$ & $p$-Value & $\mathrm{HR}(95 \% \mathrm{Cl})$ & $p$-Value & $\mathrm{HR}(95 \% \mathrm{Cl})$ & $p$-Value \\
\hline \multicolumn{7}{|c|}{ Univariate model } \\
\hline Quartile 1 & Reference & - & Reference & - & Reference & - \\
\hline Quartile 2 & $0.65(0.31-1.38)$ & 0.267 & $0.63(0.22-1.82)$ & 0.40 & $0.72(0.28-1.84)$ & 0.493 \\
\hline Quartile 3 & $1.13(0.87-1.65)$ & 0.270 & $1.15(0.74-1.79)$ & 0.54 & $1.29(0.86-1.94)$ & 0.207 \\
\hline Quartile 4 & $1.43(1.16-1.75)$ & 0.001 & $2.01(1.56-2.56)$ & $<0.001$ & $1.31(0.99-1.74)$ & 0.053 \\
\hline \multicolumn{7}{|c|}{ Multivariate model 1} \\
\hline Quartile 1 & Reference & - & Reference & - & & \\
\hline Quartile 4 & $1.46(1.16-1.83)$ & 0.001 & $2.06(1.60-2.6)^{\mathrm{a}}$ & $<0.001$ & & \\
\hline \multicolumn{7}{|c|}{ Multivariate model 2} \\
\hline Quartile 1 & Reference & - & Reference & - & & \\
\hline Quartile 4 & $1.49(1.18-1.89)$ & 0.001 & $2.34(1.57-3.47)$ & $<0.001$ & & \\
\hline
\end{tabular}

$H R$ hazard ratio, $\mathrm{Cl}$ confidence interval

Multivariate model 1: adjusted for clinical variables at baseline (age, smoker, diabetes, cardiovascular events, heart failure, systolic blood pressure), and cFGF23 quartiles

Multivariable model 2: adjusted for laboratory variables at baseline (MDRD eGFR, phosphate, albumin, haemoglobin, parathormone, cFGF23) and cFGF23 quartiles

${ }^{\text {a }}$ Multivariate model 1: adjusted for clinical variables (age, gender), and cFGF23 quartiles 

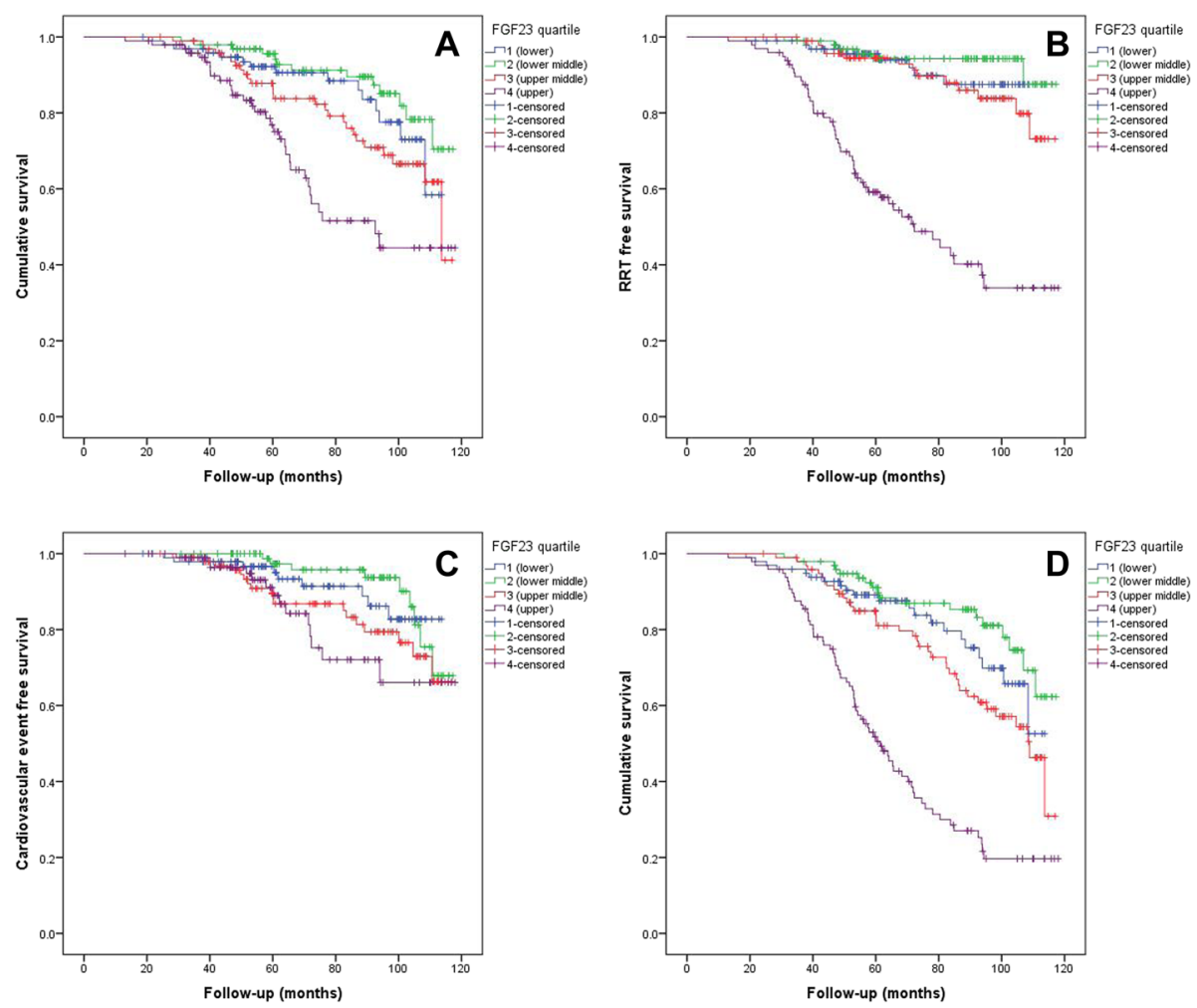

Fig. 1 Kaplan Meier graphs for event across quartiles of cFGF23. A All-cause mortality prior to renal replacement therapy. B Renal replacement therapy free survival. C Cardiovascular event free survival. D Combined outcome (renal replacement therapy and mortality)

demonstrated this in our own study population [26]. cFGF23 is highly correlated with creatinine, after adjustment for this parameter there remained a significant association between delta cFGF23 and risk for RRT. It is noteworthy that our population had advanced CKD and there was a high rate of progression to RRT. In studies that have considered the ability of baseline cFGF23 to predict progression to RRT over a fixed time frame, this marker has failed to improve model fit or discrimination with regards to this outcome measure [29].

cFGF23 was independently associated with risk for all-cause mortality in our study. These findings are consistent with analyses examining the association between baseline FGF23 and risk for death [8-10]. In studies that have looked specifically at improvements in model discrimination with the addition of FGF23, there has been an improvement in outcome prediction and reclassification with the addition of this biomarker, suggesting that it may be a valuable tool for identifying those at greatest risk [29]. The three published studies to have measured serial FGF23 have found that an increasing FGF23 is an independent risk factor for mortality $[5,7,8]$ and our study supports these findings.
Other studies have shown that FGF23 is associated with risk for fatal and non-fatal cardiovascular events [7, 9, 11-13]. Studies looking at heart failure admissions have also shown an association with baseline FGF23 [12, 37]. We were unable to demonstrate an association between delta cFGF23 and risk for non-fatal cardiovascular events in our study. Cause of death data were not available for all patients so it was not possible to explore the association between change in cFGF23 and cardiovascular death.

The potential pathophysiological mechanisms underlying the association between cFGF23, cardiovascular events and mortality have been detailed by many recent studies [14-24], but the association between cFGF23 and non-cardiovascular death $[11,38]$ requires elucidation.

The study by De Bouma et al. examined the significance of change in FGF23 levels over time in relation to baseline covariates. The investigators found that an increase in time averaged FGF23 was associated with risk for cardiovascular events, progression and death but there was no association between rate of change in FGF23 and these outcomes [7]. In the study by Isakova et al. [5] trajectory of FGF23 change was significantly associated with risk for death. Our study showed a significant association between delta cFGF23 and risk for death. 
It is important to recognize the limitations of our analysis. The SKS is an established cohort of referred patients with advanced CKD. The findings of our study may not apply to a non-referred CKD population or those with earlier stage disease. Our study was an observational study and as such cannot infer any causation on cFGF23 as regards the deleterious outcomes examined. We did not have vitamin D levels available for this analysis nor did we have data on heart failure events.

Despite the limitations of our analysis, we feel that our findings contribute to the literature on cFGF23 in CKD and confirm what has already been demonstrated in other cohorts. Our analysis has shown that increasing levels of cFGF23 are associated with all-cause mortality and risk for RRT but not non-fatal cardiovascular events in a largely Caucasian population with advanced CKD. There is a need for improved understanding of the factors influencing the levels of FGF23 and an increasing awareness of the pathophysiology of this biomarker to enhance our understanding of its associations with these outcomes. It is timely to consider the role that measurement of FGF23 could play in the management of CKD patients given the significant risks that are apparently associated with high and importantly increasing levels.

\section{Conclusion}

In our study, increasing cFGF23 was significantly associated with risk for death and and RRT but not non-fatal cardiovascular events, confirming what has already been demonstrated in other cohorts.

\section{Abbreviations}

FGF23: Fibroblast growth factor23; CFGF23: c-termina Fibroblast growth factor 23; CV: Cardiovascular; RRT: Renal replacement therapy; ONS: Office of National Statistics; SKS: The Salford kidney study; CRISIS: Chronic renal insufficiency standards implementation study; ELISA: Enzyme linked immunosorbent assay; MDRD: Modified Diet in Renal Disease.

\section{Supplementary Information}

The online version contains supplementary material available at https://doi. org/10.1186/s12882-021-02528-2.

Additional file 1: Supplementary Table 1. Cox-regression models for all-cause mortality prior renal replacement therapy (univariate model)

Additional file 2: Supplementary Table 2. Cox-regression model for renal replacement therapy (univariate model)

Additional file 3: Supplementary Table 3. Cox-regression model for cardiovascular event (univariate model)

\section{Acknowledgements}

The authors are grateful for the assistance of trials nurse Beverly Lane in relation to data and sample collection and to Dr. Robert Oliver, Dr. Kirk Siddals and Mrs. Julie Hudson in relation to sample storage and transfer. We are grateful to 'Kidneys for Life' for their support with the publication of this article.

\section{Authors' contributions}

Conception or design or Analysis and interpretation of data- TEL, AL, PJD, OA, HVA, PAK, RC. Drafting the article or revising it- STI, HVA, PAK, JPR, RM, RC. Providing intellectual content of critical importance to the work described-PJD, PAK, TEL, HVA, RC. Final approval of the version to be published- HVA, STI, OA, JPR, RM, AL, PJD, TEL, PAK, RC.

\section{Funding}

This study was part funded as an Investigator-sponsored trial supported by Shire Pharmaceuticals (BS1). The study sponsor had no role in the design of the study, data collection, data analysis, data interpretation or preparation of the report.

TE Larsson is an employee of Astellas Pharma.

\section{Availability of data and materials}

The datasets used and/or analysed during the current study are available from the corresponding author on reasonable request.

\section{Declarations}

\section{Ethics approval and consent to participate}

The NHS North West England research ethics committee (Greater Manchester South Division) has approved the study and all enrolled patients provide written informed consent (study approval number 05/Q1404/187).

\section{Consent for publication}

Not applicable.

\section{Competing interests}

All authors declare no financial or non-financial competing interested.

\section{Author details}

${ }^{1}$ Vascular Research Group, Manchester Academic Health Sciences Centre, University of Manchester, Salford Royal NHS Foundation Trust, Salford, UK. ${ }^{2}$ Department of Renal Medicine, Salford Royal Hospital, Level 2, Hope Building, Stott Lane, Salford M6 8HD, UK. ${ }^{3}$ Department of Internal Medicine and Nephrology, Faculty of Medicine, Alexandria University, Alexandria, Egypt. ${ }^{4}$ Department of Biostatistics and Medical Informatics, Acibadem Mehmet Ali Aydinlar University, Istanbul, Turkey. ${ }^{5}$ Section of Clinical Chemistry, Department of Medical Sciences, Uppsala University, Uppsala, Sweden. ${ }^{6} \mathrm{CHICAS}$, Lancaster Medical School, Lancaster University, Lancaster, UK. ${ }^{7}$ Department of Clinical Science, Intervention and Technology, Renal Unit, Karolinska Institute, Stockholm, Sweden.

Received: 16 October 2020 Accepted: 10 September 2021

Published online: 02 October 2021

References

1. Shimada T, Kakitani M, Yamazaki Y, Hasegawa H, Takeuchi Y, Fujita T, et al. Targeted ablation of Fgf23 demonstrates an essential physiological role of FGF23 in phosphate and vitamin D metabolism. J Clin Invest. 2004;113(4):561-8.

2. Quarles LD. Role of FGF23 in vitamin D and phosphate metabolism: implications in chronic kidney disease. Exp Cell Res. 2012;318(9):1040-8.

3. Ghorbanihaghjo A, Argani H, Golmohamadi Z, Rashtchizadeh N, Abbasi MM, Bargahi N, et al. Linkage of fibroblast growth factor 23 and phosphate in serum: phosphate and fibroblast growth factor 23 reduction by increasing dose of sevelamer. J Bone Metab. 2018;25(3):153-9.

4. Fukumoto $\mathrm{S}$. Targeting fibroblast growth factor 23 signaling with antibodies and inhibitors, is there a rationale? Front Endocrinol. 2018:9:48.

5. Isakova T, Cai X, Lee J, Xie D, Wang X, Mehta R, et al. Longitudinal FGF23 trajectories and mortality in patients with CKD. J Am Soc Nephrol. 2018;29(2):579-90.

6. Deo R, Katz R, de Boer IH, Sotoodehnia N, Kestenbaum B, Mukamal $\mathrm{KJ}$, et al. Fibroblast growth factor 23 and sudden versus non-sudden cardiac death: the cardiovascular health study. Am J Kidney Dis. 2015;66(1):40-6. 
7. Bouma-de Krijger A, Bots ML, Vervloet MG, Blankestijn PJ, Ter Wee PW, van Zuilen AD, et al. Time-averaged level of fibroblast growth factor-23 and clinical events in chronic kidney disease. Nephrol Dial Transplant. 2014;29:88-97.

8. Jialal I, Camacho F, Nathoo B, Tam P, Pahwa R, Wu GG. Fibroblast growth factor 23 predicts mortality and end-stage renal disease in a Canadian asian population with chronic kidney disease. Nephron. 2017;137(3):190-6.

9. Kendrick J, Cheung AK, Kaufman JS, Greene T, Roberts WL, Smits G, et al. FGF-23 associates with death, cardiovascular events, and initiation of chronic dialysis. J Am Soc Nephrol. 2011;22(10):1913-22.

10. Isakova T, Xie H, Yang W, Xie H, Anderson AH, Scialla J, et al. Fibroblast growth factor 23 and risks of mortality and end-stage renal disease in patients with chronic kidney disease. JAMA. 2011;305(23):2432-9.

11. Marthi A, Donovan $K$, Haynes R, Wheeler DC, Baigent C, Rooney CM, et al. Fibroblast growth factor-23 and risks of cardiovascular and non cardiovascular diseases: a meta-analysis. J Am Soc Nephrol. 2018;29(7):2015-27.

12. Scialla JJ, Xie H, Rahman M, Anderson AH, Isakova T, Ojo A, et al. Fibroblast growth factor-23 and cardiovascular events in CKD. J Am Soc Nephrol. 2014:25(2):349-60.

13. Seiler S, Reichart B, Roth D, Seibert E, Fliser D, Heine GH. FGF-23 and future cardiovascular events in patients with chronic kidney disease before initiation of dialysis treatment. Nephrol Dial Transplant. 2010;25(12):3983-9.

14. Grabner A, Schramm K, Silswal N, Hendrix M, Yanucil C, Czaya B, et al. FGF23/FGFR4-mediated left ventricular hypertrophy is reversible. Sci Rep. 2017:7(1):1993.

15. Leifheit-Nestler M, Große Siemer R, Flasbart K, Richter B, Kirchhoff F, Ziegler WH, et al. Induction of cardiac FGF23/FGFR4 expression is associated with left ventricular hypertrophy in patients with chronic kidney disease. Nephrol Dial Transplant. 2016;31(7):1088-99.

16. Milovanova LY, Milovanov YS, Kudryavtseva DV, Markina MM, Milovanova SY, Kozlovskaya LV, et al. Role of the morphogenetic proteins FGF-23 and klotho and the glycoprotein sclerostin in the assessment of the risk of cardiovascular diseases and the prognosis of chronic kidney disease. Ter Arkh. 2015;87(6):10-6.

17. Fragoso A, Silva AP, Gundlach K, Büchel J, Neves PL. Magnesium and FGF23 are independent predictors of pulse pressure in pre-dialysis diabetic chronic kidney disease patients. Clin Kidney J. 2014;7(2):161-6.

18. Silswal N, Touchberry CD, Daniel DR, McCarthy DL, Zhang S, Andresen J, et al. FGF23 directly impairs endothelium-dependent vasorelaxation by increasing superoxide levels and reducing nitric oxide bioavailability. Am J Physiol Endocrinol Metab. 2014;307(5):E426-36.

19. Coban M, Inci A, YIImaz U, Asilturk E. The association of fibroblast growth factor 23 with arterial stiffness and atherosclerosis in patients with autosomal dominant polycystic kidney disease. Kidney Blood Press Res. 2018;43:1160-73.

20. Yilmaz G, Ustundag S, Temizoz O, Sut N, Demir M, Ermis V, et al. Fibroblast growth factor-23 and carotid artery intima media thickness in chronic kidney disease. Clin Lab. 2015;61(8):1061-70.

21. Di Lullo L, Gorini A, Bellasi A, Morrone LF, Rivera R, Russo L, et al. Fibroblast growth factor 23 and parathyroid hormone predict extent of aortic valve calcifications in patients with mild to moderate chronic kidney disease. Clin Kidney J. 2015;8(6):732-6.

22. Singh S, Grabner A, Yanucil C, Schramm K, Czaya B, Krick S, et al. Fibroblast growth factor 23 directly targets hepatocytes to promote inflammation in chronic kidney disease. Kidney Int. 2016;90(5):985-96.

23. Rossaint J, Oehmichen J, Van Aken H, Reuter S, Pavenstädt HJ, Meersch M, et al. FGF23 signaling impairs neutrophil recruitment and host defense during CKD. J Clin Invest. 2016;126(3):962-74.
24. Nowak KL, Bartz TM, Dalrymple L, de Boer IH, Kestenbaum B, Shlipak MG, et al. Fibroblast growth factor 23 and the risk of infection-related hospitalization in older adults. J Am Soc Nephrol. 2017;28(4):1239-46.

25. Titan SM, Zatz R, Graciolli FG, dos Reis LM, Barros RT, Jorgetti V, et al. FGF23 as a predictor of renal outcome in diabetic nephropathy. Clin J Am Soc Nephrol. 2011;6(2):241-7.

26. Alderson HV, Ritchie JP, Middleton R, Larsson A, Larsson TE, Kalra PA. FGF23 and osteoprotegerin but not Fetuin-a are associated with death and enhance risk prediction in non-dialysis chronic kidney disease stages 3-5. Nephrology (Carlton). 2016;21(7):566-73.

27. Rebholz CM, Grams ME, Coresh J, Selvin E, Inker LA, Levey AS, et al. Serum fibroblast growth factor-23 is associated with incident kidney disease. J Am Soc Nephrol. 2015;26(1):192-200.

28. Drew DA, Katz R, Kritchevsky S, Ix JH, Shlipak MG, Newman AB, et al. Fibroblast growth factor 23: a biomarker of kidney function decline. Am J Nephrol. 2018;47(4):242-50.

29. Levin A, Rigatto C, Barrett B, Madore F, Muirhead N, Holmes D, et al. Biomarkers of inflammation, fibrosis, cardiac stretch and injury predict death but not renal replacement therapy at 1 year in a Canadian chronic kidney disease cohort. Nephrol Dial Transplant. 2013;29(5):1037-47.

30. Smith ER, Cai MM, McMahon LP, Holt SG. Biological variability of plasma intact and C-terminal FGF23 measurements. J Clin Endocrinol Metab. 2012;97:3357-65.

31. Damasiewicz MJ, Lu ZX, Kerr PG, Polkinghorne KR. The stability and variability of serum and plasma fibroblast growth factor-23 levels in a haemodialysis cohort. BMC Nephrol. 2018;19(1):325.

32. Ritchie J, Assi LK, Burmeister A, Hoefield R, Cockwell P, Kalra PA. Association of serum Ig free light chains with mortality and ESRD among patients with nondialysis-dependent CKD. Clin J Am Soc Nephrol. 2015;10(5):740-9.

33. Ritchie J, Rainone F, Green D, Alderson H, Chiu D, Middelton R, et al. Extreme elevations in blood pressure and all-cause mortality in a referred CKD population: results from the CRISIS study. Int J Hypertens. 2013;2013:597-906.

34. Hoefield RA, Kalra PA, Lane B, O'donoghue DJ, Foley RN, Middleton RJ. Associations of baseline characteristics with evolution of eGFR in a referred chronic kidney disease cohort. QJM. 2013;106(10):915-24.

35. Eddington H, Hoefield R, Sinha S, Chrysochou C, Lane B, Foley RN, et al. Serum phosphate and mortality in patients with chronic kidney disease. Clin J Am Soc Nephrol. 2010;5(12):2251-7.

36. Levey AS, Bosch JP, Lewis JB, Greene T. A more accurate method to estimate glomerular filtration rate from serum creatinine: a new prediction equation. Ann Intern Med. 1999;130(6):419.

37. Seiler S, Rogacev KS, Roth HJ, Shafein P, Emrich I, Neuhaus S, et al. Associations of FGF-23 and sKlotho with cardiovascular outcomes among patients with CKD stages 2-4. Clin J Am Soc Nephrol. 2014;9(6):1049-58.

38. Souma N, Isakova T, Lipiszko D, Sacco RL, Elkind MS, DeRosa JT, et al. Fibroblastgrowth factor 23 and cause-specific mortality in the general population: the northern Manhattanstudy. J Clin Endocrinol Metab. 2016;101:3779-86.

\section{Publisher's Note}

Springer Nature remains neutral with regard to jurisdictional claims in published maps and institutional affiliations. 